\title{
INCLUSÃO DIGITAL E INOVAÇÃO PEDAGÓGICA: DIÁLOGO NECESSÁRIO
}

\author{
INCLUSIÓN DIGITAL E INNOVACIÓN PEDAGÓGICA: DIÁLOGO \\ NECESSÁRIO
}

\author{
DIGITAL INCLUSION AND PEDAGOGICAL INNOVATION: NECESSARY \\ DIALOGUE
}

\author{
Rejany dos Santos DOMINICK ${ }^{1}$ \\ Walcéa Barreto ALVES ${ }^{2}$
}

RESUMO: Buscamos compreender as tecnologias e sua relação com o ensino, pois, nas escolas, as tecnologias tradicionais prevalecem, enquanto fora dela mergulha-se no "novo mundo", em que artefatos cada vez mais complexos e que demandam novas formas de organização e produção de conhecimentos são criados. Dialogamos com abordagens teórico-metodológicas da Pesquisa Participante, Etnografia e Tecnologia Social, bem como a Teoria das Representações Sociais para refletirmos sobre a inclusão digital de alunos da educação básica e de docentes em formação inicial e continuada, em Niterói-RJ. Resultados explicitam algumas dificuldades para o estabelecimento de diálogos entre novas e tradicionais tecnologias nas práticas pedagógicas. Contudo, há reinvenções que dão pistas sobre o nascimento de uma pedagogia inovadora.

PALAVRAS-CHAVE: Tecnologias digitais. Inclusão digital. Inovação pedagógica. Pesquisa participante. Pesquisa etnográfica.

RESUMEN: Buscamos comprender las tecnologías y su relación en la enseñanza, pues en las escuelas, las tecnologías tradicionales prevalecen, mientras que fuera de ella, se sumerge en el "nuevo mundo", donde artefactos cada vez más complejos y que demandan nuevas formas de organización y producción de conocimientos son creado. Los enfoques teorico-metodológicos con los que dialogamos son la Investigación Participante, Etnográfica y Tecnología Social, así como con la Teoría de las Representaciones Sociales para reflexionar sobre la inclusión digital de alumnos de la educación básica y de docentes en formación inicial y continuada, en Niterói-RJ. Los resultados explicitan algunas dificultades para el establecimiento de diálogos entre nuevas y tradicionales tecnologías en las prácticas pedagógicas. Sin embargo, hay reinvenciones que dan pistas sobre el nacimiento de una pedagogía innovadora.

${ }^{1}$ Universidade Federal Fluminense (UFF), Niterói - RJ - Brasil. Professora Associada - Faculdade de Educação - Departamento Educação, Sociedade e Conhecimento; Curso de Mestrado Profissional em Diversidade e Inclusão (CPMDI/UFF). ORCID: <https://orcid.org/0000-0003-0456-4201>. Email: rejany.dominick@gmail.com

2 Universidade Federal Fluminense (UFF), Niterói - RJ - Brasil. Professora Adjunta - Faculdade de Educação - Departamento Educação, Sociedade e Conhecimento; Programa de Pós-Graduação em Mídia e Cotidiano (PPGMC/UFF). ORCID: <https://orcid.org/0000-0001-8294-917X>. Email: walceaalves@id.uff.br 
PALABRAS CLAVE: Tecnologías digitales. Inclusión digital. Innovación pedagógica. Investigación participante. Investigación etnográfica.

ABSTRACT: We are working to understand the technologies and their relationship in teaching, because in schools, traditional technologies prevail, while outside of it, we are immersed in a "new world" where increasingly complex artifacts that demand new forms of organization and production of knowledge. Our theoretical-methodological basis dialogues with the Theory of Social Representations, with Participating and Ethnographic Researches and with Social Technology by studying aspects of digital inclusion of students on basic education and teachers in initial and continued formation in Niterói City, Rio de Janeiro. Some research results explain aspects of the difficulties encountered by the teachers in order to concretize the dialogue between the new and traditional technologies in their pedagogical practices. However, reinventions provide clues to a democratic, innovative, inclusive education.

KEYWORDS: Digital technologies. Digital inclusion. Pedagogical innovation. Participant research. Ethnographic research.

\section{Introdução}

As pesquisas que serão apresentadas neste texto apoiam-se na perspectiva de uma educação para a inclusão da diversidade e articulam tais questões às tecnologias - novas e tradicionais - a partir de aproximações e interações entre a universidade e a escola básica. A coleta de dados tem sido feita por meio de atividades de pesquisa, de ensino e de extensão na Universidade Federal Fluminense (UFF) e em duas instituições de ensino da rede municipal de Niterói, localizada na região metropolitana do Rio de Janeiro. A equipe é formada por professoras e estudantes de licenciaturas e pós-graduação da Faculdade de Educação da UFF em diálogo com os professores e alunos das escolas pesquisadas.

Os estudos desenvolvidos emergem do entendimento de que as tecnologias digitais estão presentes de maneira contundente na vivência cotidiana de grande parte dos indivíduos na contemporaneidade. A compreensão do ciberespaço como contexto de utilização e veiculação de informação via uso das tecnologias digitais e das redes apresenta possibilidades de interação, construção e acesso ao conhecimento e às informações que, segundo Lévy (1999), produzem significações, linguagens e "modos de uso" que caracterizam o que se denomina cibercultura.

Desde a primeira Revolução Industrial, temos produzido artefatos cada vez mais complexos para substituir as ferramentas que usavam a força humana ou animal por aquelas que demandam uma organização de conhecimentos complexos. Seguindo um 
caminho não muito linear, surgem a imprensa, a eletricidade, as tecnologias da comunicação como rádio, telégrafo, telefone, cinema e outras tantas invenções. Hoje, convivemos com a tecnologia digital, também denominada como nova tecnologia, mas os artefatos e métodos anteriores (velhas tecnologias) ainda estão presentes na escola.

Visando o estudo de aspectos diversos da inclusão digital, conectamo-nos com alunos da educação básica e docentes em formação inicial e continuada. Buscamos compreender as tecnologias e sua relação com os atores sociais na escola e na universidade. Partimos da constatação de que algumas políticas públicas de inclusão digital propostas pelos governos federal e municipal não estão todas conectadas à perspectiva de formação de sujeitos interagentes e em diálogo com as demandas reais de profissionais e estudantes. Temos observado que nem todas as políticas governamentais envolveram de forma efetiva professores e estudantes no processo de construção de conhecimentos sobre os usos das tecnologias informacionais.

Assim, buscamos aprofundar conhecimentos com os atores sociais em duas escolas do ensino fundamental. Visamos valorizar iniciativas que emergissem de professores, estudantes das escolas e estudantes das licenciaturas, para gerar um conhecimento autossustentado e que possibilitasse a transformação de práticas pedagógicas ainda articuladas aos padrões dominantes. Tais iniciativas foram identificadas como inovadoras no contexto da prática educacional, inclusive em nossa prática de docentes do ensino superior.

Por meio de projetos de pesquisa, ensino e extensão, estudantes e professores da UFF se apropriaram de princípios das tecnologias sociais para o trabalho. São princípios da tecnologia social: o atendimento de demandas do grupo envolvido; as interações sociais de sujeitos de diferentes campos do conhecimento e com diversidade de saberes; envolvimento de atores públicos e privados; promoção de desenvolvimento e sustentabilidade socioeconômica e ambiental; fortalecimento e estímulo à organização com participação social e política, proporcionando a inclusão social por meio da geração de trabalho e renda. Na visão de Costa e Jesus (2013, p. 18),

O termo "tecnologia social" é pensado de forma ampla para as diferentes camadas da sociedade. O adjetivo "social" não tem a pretensão de afirmar somente a necessidade de tecnologia para os pobres ou países subdesenvolvidos. Também faz a crítica ao modelo convencional de desenvolvimento tecnológico e propõe uma lógica mais sustentável e solidária de tecnologia para todas as camadas da sociedade. Tecnologia social implica participação, empoderamento e autogestão de seus usuários

RIAEE - Revista Ibero-Americana de Estudos em Educação, Araraquara, v. 13. n. esp. 2, p. 1334-1358, set., 2018. ISSN: 1982-5587. 
- princípios-base do conceito utilizado nesta pesquisa. No entanto, dada a realidade da América Latina, tem seu potencial conceitual debatido e expandido para estratégias concretas de inclusão social.

No mundo contemporâneo, a cada novo momento são produzidos conhecimentos e artefatos cada vez mais complexos, que demandam novas formas de organização e de interação, mas nem todas as pessoas têm acesso a eles em igualdade de condições, tendo respeitadas suas singularidades e direitos. Embora tais conhecimentos e artefatos sejam produções humanas, a forma de organização social ainda conduz a que estes sejam apropriados por uma pequena parte dos indivíduos da sociedade brasileira. Artefatos como celulares são mais acessíveis a todos, mas a inclusão digital deve ser pensada como algo que vai além da aquisição individual de celulares. Concordamos com Castells (1999a) quando afirma que vivemos na sociedade da informação. Hoje, temos a compreensão de que a partir das décadas de 1960 e 1970 surgiu "um novo mundo" (CASTELLS, 1999a), no qual contextos sociais diversos, economias e culturas se interligaram por meio dos avanços das tecnologias da informação e da comunicação (TICs), fazendo surgir uma sociedade em rede, informacional. Contudo, os artefatos são gerados na cultura e eles próprios transformam nossa maneira de ser e estar no mundo. Somos nós, seres humanos, quem lidamos com a informação e o conhecimento no contexto dos avanços tecnológicos produzimo-los e somos alcançados e "afetados" por eles.

Diante do que se apresenta na contemporaneidade, lidamos dialeticamente com questões de autonomia e heteronomia, democracia e autoritarismo, liberdade e controle. Percebe-se que as novas gerações têm vivenciado e participado de maneira mais direta e intensa das mudanças que vêm se desencadeando e que influenciam o comportamento, o relacionamento social e, assim, o modo como o indivíduo enxerga o mundo e aprende com ele. As tecnologias informacionais trouxeram novas formas de acesso ao conhecimento: hipertextos digitais que ampliam significativamente as possibilidades de exploração e dinamização dos processos cognitivos e sociais; redes digitais interativas que permitem aos indivíduos o compartilhamento de saberes de forma instantânea. Nesse cenário, a cibercultura torna-se identitária dos processos de fruição e contextualização das ações em rede, configurando perspectivas sociais de interação, interatividade, colaboração e conectividade (LÉVY, 1999), criando dinâmicas que possibilitam diferenciados mecanismos de raciocínio e desenvolvimento do processo de aprendizagem, possibilitando maior fluidez e sinergia nas trocas e produção de conteúdos. 
Mediante esse contexto, a temática deste estudo será abordada a partir dos seguintes questionamentos: Quais são as relações estabelecidas entre a acessibilidade às tecnologias digitais e os processos de ensino e aprendizagem em sala de aula? Qual tem sido a implicação e a participação dos alunos e professores na construção do conhecimento - referente à aquisição dos conteúdos escolares - baseada no uso das tecnologias e das redes? No contexto da educação formal, como o aluno e o professor estão lidando em seu dia a dia com um universo que vai além dos muros da instituição escolar tradicional? Como têm se incorporado as novas tecnologias nos processos pedagógicos?

Partindo de tais questionamentos e proposições, nossas interações teóricas se colocaram em um campo crítico e desenvolvem, neste artigo, diálogos sobre a formação de professores para a inclusão digital e a problematização acerca da inserção dos estudantes da educação básica perante as novas formas de aprender e explorar conhecimentos no contexto da cibercultura.

\section{O mundo informacional no qual estamos mergulhados}

O novo mundo do qual nos fala Castells (1999a) é caracterizado por uma economia interdependente, no qual as tecnologias da comunicação e da informação têm um importante papel para o surgimento do que o autor denomina de capitalismo informacional ou capitalismo cognitivo, que se efetiva nos anos 1980. Contudo, todo processo de mudança tem em si o novo e o velho. Com as tecnologias informacionais não tem sido diferente e, no início do século XXI, elas têm assumido tanto o papel de reprodução da sociedade de classes como de mobilização social daqueles e daquelas que não hegemonizam os processos econômicos e culturais no planeta. Pela mão de alguns usuários das redes sociais, as tecnologias tornam-se um instrumento de denúncia e de reivindicação de direitos políticos, potencializando a construção de uma sociedade mais democrática, plural e includente.

Castells (1999b) também afirma que as novas tecnologias, seus usos e desenvolvimento são muito rápidos, levando a uma difusão amplificada, quase que de forma infinita, à medida que os usuários delas se apropriam e as redefinem. $\mathrm{O}$ autor declara que "usuários e criadores podem tornar-se a mesma coisa. Dessa forma, os usuários e criadores podem assumir o controle da tecnologia como no caso da Internet [...]" (p. 69). 
Coadunando com essa perspectiva, observam-se os conceitos de inteligência coletiva de Lévy (1999) e de organização horizontal em rede, de Pretto e Assis (2008), que apresentam elementos enriquecedores à discussão sobre o uso das redes, seu impacto nos processos sociais e as possibilidades de novas configurações de articulação da sociedade civil rumo à criação de redes colaborativas, integradas, que podem assumir, em sua própria essência, um caráter democrático e, ao mesmo tempo, “democratizador”, em contraposição a uma “organização vertical de comando". Segundo Pretto e Pinto (2006, p. 20),

[...] as redes de computador podem oferecer suporte propício para que essa organização horizontal funcione de forma mais ampla envolvendo recursos distribuídos em regiões muito extensas, como a totalidade do planeta, e um grande número de pessoas [...].

Os autores apontam para um tipo de organização social que potencialize iniciativas e soluções coletivas e públicas, mediante ação em rede, numa perspectiva de ampla participação popular nas decisões, até mesmo aquelas de fundo estrutural na sociedade. As ações voltadas para a democracia e construção de estratégias seriam mobilizadas dentro de um programa político e cultural (não no sentido clássico do termo) voltado para valores essenciais como a autonomia e a abertura para a alteridade (LÈVY, 1999). No entanto, Pretto e Pinto (2006) asseveram que um grande impasse para a concretização de um projeto como esse no contexto do Brasil é composto por entraves à popularização do acesso à Internet - considerada peça-chave - e às ferramentas digitais. No cenário atual, observa-se que a hierarquização social é projetada e vivenciada no ambiente virtual, mediante as dificuldades de acesso à rede por grande parte das classes populares nas regiões metropolitanas e nas cidades interiorizadas. Em grande proporção, há populações que têm o acesso restrito a espaços específicos (como escola, trabalho, lan houses, entre outros), com mídias que, em grande parte das vezes, não são de sua propriedade, retratando aspectos que se enquadram num processo de exclusão digital.

Nesse cenário, entre outras questões, aponta-se para a necessidade premente de que sejam desenvolvidas políticas públicas que superem a limitação do acesso independente e individualizado às redes nas residências, normalmente mais elitizado e restrito àqueles que têm maior recurso financeiro.

Para Pretto e Pinto (2006), há ainda outros elementos que servem de barreira para a inclusão digital e estes se relacionam à concentração da propriedade dos meios de comunicação de massa por grupos específicos, que monopolizam e manipulam a 
distribuição de imagens e informações, introduzindo concepções voltadas para o consumismo, que influenciam a educação e a cultura, imprimindo uma perspectiva individualista e, por assim dizer, mais propensa à heteronomia na atuação social.

Diante desse panorama, vemo-nos frente a dicotomias que poderiam nos colocar a favor ou em oposição à cibercultura. No entanto, o contexto atual permite-nos cambiar por essas dimensões criticamente, analisando o ciberespaço como um lugar de possibilidades e limitações na ampliação de ação e transformação via interconectividade e interatividade entre seus usuários. Lèvy (1999), como ele mesmo afirmou em sua obra, apresenta uma visão otimista do alcance e potencialidade das redes, apontando entremeares que circunvizinham as ações e interconexões viabilizadas no ciberespaço:

\begin{abstract}
Quanto mais o ciberespaço se estende, mais universal se torna, menos totalizável o mundo informacional se torna. O universal da cibercultura está tão desprovido de centro como de linha diretriz. [...] Eu não quero dizer com isso que a universalidade do ciberespaço seja "neutra" ou sem consequências, pois o fato-mor do processo de interconexão geral já tem e terá ainda mais, no futuro, imensas repercussões na vida econômica, política e cultural. [...] Essa universalidade desprovida de significado central, esse sistema da desordem, essa transparência labiríntica, eu a chamo o "universal sem totalidade". Constitui a essência paradoxal da cibercultura (LÈVY, 1999, p. 111).
\end{abstract}

Com base numa concepção elitista, sustenta-se, em contextos mais amplos, que todos estamos, por meio das mais variadas mídias digitais - entre as quais as mais popularizadas são os smartphones -, conectados a uma aldeia global, sendo "cidadãos do mundo". Entretanto, no contexto das pesquisas que realizamos, denota-se que os mecanismos de acesso às tecnologias digitais e às redes têm uma restrição significativa atravessada pelo recorte de classe social.

Embora estejamos diante de todos esses dilemas, fica perceptível nas práticas cotidianas dos sujeitos contemporâneos a presença da cibercultura e de mudanças que ocorrem nas formas de viver, sentir, saber e construir conhecimentos.

No contexto do uso das mídias digitais, realizamos constantemente simultâneas e múltiplas conexões. Diante da interconectividade das redes, lidamos com um sistema de comunicação em que perfazemos caminhos de exploração, pesquisa e interação segundo nossas necessidades, curiosidades, preferências e aptidões. O ciberespaço, os dispositivos tecnológicos e suas ferramentas apresentam novas vias de saber, abrindo uma infinidade de possibilidades educacionais. Sabemos também que as TICs não podem ser simplesmente ferramentas a serem aplicadas pelos docentes, substituindo os velhos artefatos. A sua 
inserção implica uma alteração na forma de ser professor. É preciso que os docentes se apropriem delas como mediadores entre conhecimento e estudantes, assumindo em seu trabalho outro papel e dialogando com a cultura do compartilhamento.

A cultura do compartilhamento é uma racionalidade inovadora, pois está baseada na ética hacker que, na visão de Bonilla e Pretto (2015), busca a troca de informações livremente, possibilitando a criação das novas formas de relacionamento social. Dialoga com uma perspectiva contrária ao consumismo e ao individualismo tão presentes na cultura contemporânea. É uma apropriação do espaço e dos conteúdos da internet de forma livre, democrática e gratuita. Sob esse paradigma, os acessos aos conhecimentos disponíveis podem propiciar situações nas quais os humanos são percebidos como interagentes e não apenas como consumidores acríticos, interagidos pelas mídias eletrônicas.

Ao nos remetermos aos mecanismos de cognição engendrados no contexto da realidade virtual, precisamos refletir sobre o papel das instituições educativas na formação de indivíduos interagentes.

Há cerca de duas décadas, Lèvy (1999, p. 172) já apontava que o ponto nodal estava na "mudança qualitativa dos processos de aprendizagem". Ele preconizava uma mudança paradigmática, visto que a sociedade (diante da cibercultura) estava caminhando para uma forma mais profunda de aprendizagem cooperativa. Nesse sentido, os processos desenvolvidos no contexto das instituições educativas deveriam coadunar com a exploração e troca de informações entre professores, alunos e toda a comunidade escolar numa produção coletiva, mediada pelo uso da rede.

O que constatamos na atualidade é que, em grande parte, as práticas educacionais desenvolvidas nas escolas estão em dissonância com essa proposta, distanciando-se dos modos como nossos alunos (e professores) têm vivenciado os mecanismos interativos no ambiente social. Ainda estamos distantes dos processos de inovação pedagógica voltados para o ensino e para a formação de professores com enfoque nessa transição de paradigma, que vai além da inserção e apropriação de ferramentas e recursos tecnológicos.

Isso significa que não podemos nos contentar com simples apropriações dessas tecnologias, como se elas fossem, por si sós, capazes de reverter situações. É por isso que precisamos enxergar que, com essas potencialidades, pululam elementos que, longe de serem unificadores, constituem-se em diferenciadores dos seres e de suas culturas, passando a polos geradores de novas articulações (PRETTO; PINTO, 2006, p. 23). 
No entanto, para gerar uma ruptura cultural nas escolas, é indispensável que haja um projeto que possibilite a formação de novos professores com postura de sujeitos interagentes (CASTELLS, 2002). Na sociedade de hoje, em razão das demandas de uso obrigatório das novas tecnologias (cartão de ônibus e banco, telefone celular e outros artefatos), nós as utilizamos, mas não exploramos suas possibilidades e não refletimos sobre suas contribuições, limites e imposições. Nessa perspectiva, como professores, acabamos, por vezes, agindo - mesmo quando incluímos um datashow em nossas aulas como sujeitos interagidos pelas tecnologias e pelas demandas externas das grandes corporações e grupos dominantes.

Uma formação inovadora deve possibilitar uma transposição desse lugar de quem apenas aceita as tensões sociais e cognitivas propostas pelas novas tecnologias e passa a interagir com elas de forma a descobrir e redescobrir possibilidades, reinventando métodos e artefatos na educação que possibilitem a inclusão digital em uma sociedade em que a desigualdade social seja questionada e superada.

\section{Inovação pedagógica e inclusão digital}

Gatti (2016, p.165), abordando o cenário social brasileiro, que por ela é definido como de desigualdades culturais excessivas, explicita:

É vigente a ideia de que posse de conhecimentos é um dos determinantes de desigualdades sociais. Ela se mostra como princípio diferenciador de pessoas e grupos humanos. Deter certos conhecimentos é poder obter vantagens e facilidades no movente mundo atual. Há conhecimentos que estão na base de ações que podem trazer melhores condições de acesso a bens sociais valorizados, conhecimentos que são relevantes socialmente e que têm conotações específicas em ambientes diversificados.

Para a autora, é preciso articular a essa concepção o fato de que nos processos educacionais não estão envolvidos apenas os conhecimentos estritos, advindos das ciências ou de aspecto instrumental, mas " [...] um conjunto mais amplo de meios de construção de compreensões que possibilitam viver melhor" (GATTI, 2016, p. 165). Identificando a sociedade brasileira como em processo de passagem "de uma sociedade industrial para uma sociedade da informação, de uma sociedade segura para uma sociedade plural e instável” (GATTI, 2016, p. 165), ela nos lembra de que o desenvolvimento profissional dos docentes nos tempos atuais demanda saberes que vão muito além de competências operativas e técnicas. Vai tornando-se indispensável ao professor ser capaz de mobilizar 
"conhecimentos e métodos de trabalho, intenções, valores individuais e grupais, da cultura da escola"; confrontar "ideias, crenças, práticas, rotinas, objetivos e papéis, no contexto do agir cotidiano, com seus alunos, colegas, gestores, na busca de melhor formar as crianças e jovens, e a si mesmos" (GATTI, 2016, p. 169). Em uma sociedade

[...] que se delineia como informático-cibernética a educação é chamada a priorizar o domínio de certas habilidades a ela relacionadas e os que não possuem as habilidades para tratar a informação, ou não têm os conhecimentos que as redes valorizam, ficam totalmente excluídos. Fossos e diferenciações entre grupos humanos estão abertos. Assim, as ações educacionais, formais ou não, estão em questão e colocam-se entre propiciar a transformação ou exacerbar a exclusão. O desafio está posto: que sociedade buscamos, que escola precisamos ter, quais professores para nela atuar? (GATTI, 2016, p. 165).

Sabemos que a maioria dos alunos de classe alta e média possui acesso mais fácil à internet e a conhecimentos que possibilitam lidar com o mundo atual permeado pelas novas tecnologias. Estes exploram desde muito cedo, de forma ampla e livre, ambientes digitais. Vivenciam a cultura, a interatividade e, até mesmo, participam de certas produções colaborativas, mas os alunos das classes populares ainda têm limitada a sua acessibilidade a esses ambientes virtuais de produção e troca de conhecimento. Contudo, mesmo de forma limitada, estão imersos em uma sociedade cibercultural e precisam desenvolver suas habilidades cognitivas para não serem perpetuadas exclusões culturais e socioeconômicas. Mamede-Neves e Duarte (2008, p. 75) apontam como fundamental:

[...] entender a relação que crianças e jovens têm com essas tecnologias, como as utilizam e para que, como aprendem e o que aprendem em contato com elas, ao invés de proibir seu uso na escola, pode nos ajudar a encontrar maneiras de incorporá-las, de forma mais adequada e produtiva, aos ambientes e práticas escolares.

A partir dos apontamentos supra, entende-se como relevante a inserção de professores e estudantes das licenciaturas no contexto escolar a fim de ouvir, conhecer e desenvolver estratégias com os atores escolares, no sentido de compreender, aprender e buscar práticas inovadoras que dialoguem com a perspectiva da inclusão digital, tão necessária ao contexto contemporâneo.

\section{O aluno, a escola e as tecnologias - caminhos para práticas emancipatórias?}


Neste tópico abordamos o desenvolvimento da pesquisa "Representações sociais, tecnologias digitais e o contemporâneo: investigando a escola", realizada pelo Núcleo de Estudos Contemporâneos em Educação, Etnografia e Representações Sociais (NECEERS/UFF). O lócus da investigação é uma escola da rede municipal de educação de Niterói, RJ. Os participantes primários são alunos de uma Classe de aceleração do $3 .^{\circ}$ Ciclo do Ensino Fundamental. Os participantes secundários são professores, gestores, funcionários e pais de alunos da escola pesquisada. O princípio investigativo é a perspectiva bottom-up - uma inversão piramidal do olhar para as questões educacionais, partindo-se da base (o aluno) para o topo (gestores educacionais). A partir dessa concepção, a pesquisa desenvolve-se priorizando a voz de alunos em suas significações sobre a escola, o papel do uso das tecnologias digitais na contemporaneidade e suas repercussões nos processos de interação e nas práticas educativas. A pesquisa é pautada na perspectiva multimétodos de investigação (mixed research) (GÜNTHER; ELALI; PINHEIRO, 2008; JOHNSON; ONWUEGBUZIE, 2004), sendo a abordagem etnográfica o eixo metodológico principal (MATTOS, 2001, 2006, 2009). Como aporte teóricometodológico, a Teoria das Representações Sociais (MOSCOVICI, 2003; JODELET, 2001; ABRIC, 1994, 2000) consiste no referencial para embasar a investigação a respeito dos encontros - e também desencontros - entre o individual e o social na dinâmica do processo educativo. Acreditamos que as representações sociais dos alunos sobre a escola e as tecnologias digitais no contexto contemporâneo tenham interface com os processos de ensino-aprendizagem que acontecem no cotidiano escolar, servindo de base para analisarmos as interações, significações e suas repercussões no contexto educacional. Pretende-se, a partir dessa perspectiva, ouvir a voz do aluno, buscando potencializar o desenvolvimento de estratégias de ação coletiva e colaborativa. Entendendo-o como agente prospectivo de mudança, pretende-se vislumbrar práticas de inovação pedagógica que promovam emancipação e inclusão.

A pesquisa encontra-se em fase de análise dos dados que foram produzidos durante o trabalho de campo, mediante observação participante, realização de grupo focal e aplicação de questionário de evocação livre. As análises são orientadas pelas dimensões das representações sociais, a atitude, a informação e o campo de representação, empregando-se a metodologia de análise de conteúdo (BARDIN, 2006).

No momento atual, apontamos análises preliminares considerando as dimensões discursivas e atitudinais dos participantes, situadas no contexto da pesquisa. 
Os dados apontam para o fato de que os alunos utilizam tecnologia em seu cotidiano relacionada à rede, em específico ao uso das redes sociais, práticas com games e acesso a vídeos, músicas e séries. A mídia mais utilizada é o aparelho celular, com seus “indispensáveis" fones de ouvido.

Os alunos apontaram que a tecnologia está presente nos processos educativos formais quando se desenvolvem projetos específicos que utilizam o laboratório de informática, o que não ocorre comumente nas salas de aula, que se mantêm mais relacionadas a métodos de ensino que se distanciam das novas formas de dinamizar informações e construir conhecimentos no contexto da cibercultura. $\mathrm{O}$ uso das tecnologias em sala de aula é realizado pelos alunos de maneira dissociada da dinâmica proposta pelos professores relativamente aos conteúdos escolares. Esses usos, normalmente, são relacionados a acesso a jogos, músicas, aplicativos de mensagens instantâneas (como, mais comumente, Whatsapp e Messenger) e a redes sociais (em especial, o Facebook), ocorrendo em ocasiões que os alunos não se sentem sob a "vigilância" direta do professor, visto que cartazes afixados na escola indicam a proibição do uso do celular em sala de aula.

Durante a pesquisa, acompanhamos, nesta turma, um projeto de robótica fomentado pela Fundação Municipal de Educação de Niterói e coordenado pela professora de Artes da escola, em articulação com os professores de ciências e matemática. O projeto ocorreu no laboratório de informática e na sala de artes. Os alunos utilizaram os computadores para assistirem e acompanharem os tutoriais para a montagem de peças, assim como para realizarem a parte de programação para movimentação delas.

Em entrevista tipo grupo focal, os alunos assinalaram que a interface da escola com a tecnologia se deu exclusivamente pelo projeto de robótica, avaliando-o como importante e válido para a aquisição de conhecimentos relevantes. O projeto obteve resultados que se repercutiram dentro e fora da escola (participação em feira de robótica, com premiação pela FME-Niterói).

De acordo com os dados e análise preliminar, vislumbramos como fundamental a realização de estreitamento do entendimento sobre o que representa a utilização dos aparatos tecnológicos para os alunos, de que maneira eles se apropriem - ou não - dos usos e desusos das tecnologias no contexto escolar. Ouvir, estar atento às suas falas e apontamentos, é um importante passo para a compreensão sobre as redes de significação que atravessam seus cotidianos e quais impactos estas têm no processo de ensino- 
aprendizagem e dimensionamento do lugar da tecnologia no cotidiano, no contexto escolar e na sala de aula.

Os dados da pesquisa demonstram que a relação da tecnologia com a escola deve partir da compreensão de que os aparatos tecnológicos desenvolvem um papel mais amplo do que sua instrumentalidade, visto que, enquanto recurso por si só, não definem as potencialidades da ação humana, mas são transformados por ela. Ações em coletividade e colaboração entre alunos e professores podem potencializar a reflexividade nos processos de construção de conhecimento e produção de saberes no contexto contemporâneo do cotidiano escolar e da cibercultura, mediadas pelas possibilidades de descoberta e produção de conhecimento que se faz subsequente à ação e intencionalidade humana. Diante dessas análises iniciais, vislumbram-se perspectivas de produtivas trocas entre os saberes acadêmicos e os saberes escolares para a promoção de práticas emancipatórias e ressignificação dos espaços-tempos escolares.

\section{Inovação, inclusão digital e formação de professores}

A outra pesquisa vem sendo realizada desde 2011 por meio de Projetos nas Escolas (PE), desenvolvidos a partir dos caminhos propostos pelas teorias interativas explicitadas nas produções de Brandão (1987, 1990, 2003), Ludke e André (1986), Thiollent (1994), entre outros.

Os Projetos nas Escolas acontecem a partir de um tema definido pelos interesses dos graduandos em licenciaturas em diálogo com o projeto gerador. A partir do contato dos licenciandos com a escola, os projetos ganham contornos dos diálogos específicos de cada realidade e se efetivam.

As atividades realizadas devem estar articuladas ao planejamento do professor coordenador, pois nos movimentamos em direção aos sujeitos, uma vez que "toda pesquisa-ação possui um caráter participativo, pelo fato de promover ampla interação entre pesquisadores e membros representativos da situação investigada" (THIOLLENT, 1994, p. 21). O pesquisador aprende sobre si mesmo e se transforma, aprende sobre o outro e identifica que o outro se transforma ao transformar.

Partindo da perspectiva da Tecnologia Social (ITS, 2004), a proposta dialoga com os interesses locais e são buscados pontos de conexão entre os objetivos de ensino e de pesquisa - traçados pelos licenciandos - e os objetivos do projeto de pesquisa gerador e as

RIAEE - Revista Ibero-Americana de Estudos em Educação, Araraquara, v. 13. n. esp. 2, p. 1334-1358, set., 2018. ISSN: $1982-5587$. 
demandas locais. É criada uma trama na qual pesquisa-ensino-extensão geram tanto a produção quanto a construção de conhecimentos pelos e com os estudantes da educação básica, estudantes de licenciatura, profissionais da escola e da universidade.

O PE acontece por meio de ações planejadas e algumas inesperadas, que ocorrem de acordo com as demandas e interações surgidas no campo. Em reuniões semanais na UFF e mensais na escola são elaboradas reflexões sobre os acontecimentos.

Em 2011, por meio do projeto gerador apresentado à Agência de Inovação da UFF-PROPPI, denominado “As 'artes de fazer' a educação em ciclos: diálogos entre tecnologias na formação de professores", aprofundamos nosso diálogo entre a formação de professores, as tecnologias informacionais e a inovação.

A partir de 2016, passamos a desenvolver o projeto "Novas e tradicionais tecnologias nos anos iniciais da educação básica e a formação de professores", que vem buscando construir e aprofundar conhecimentos com os professores em formação inicial e continuada sobre as novas e tradicionais tecnologias presentes nas práticas educativas.

Nesses anos, os dados coletados e as experiências inovadoras produzidas foram significativas. Vamos destacar aqui alguns aspectos identificados como limitadores e potencializadores da inclusão digital e de uma pedagogia inovadora.

Do nosso ponto de vista, uma pedagogia inovadora demanda que o professor deixe de se perceber como um transmissor de saberes, como nos velhos esquemas das escolas modernas, e transforme-se em um mediador que propõe questões, provoca o pensar dos participantes para um trabalho de experiências de construção de conhecimento compartilhadas, colaborativas e sistematizadas singularmente por cada um e de forma coletiva. Há uma ruptura com a lógica do falar-ditar do mestre, abrindo-se espaço para o exercício da participação genuína que, para Silva (2010, p. 44), é a

[...] participação sensório-corporal e semântica e não apenas mecânica. Capaz de superar a centralidade da modalidade tradicional de aprendizagem, em favor da aposta na modalidade interativa, da dinâmica comunicacional da cibercultura e da educação autêntica.

Visando o uso das tecnologias digitais de maneira inovadora na escola, numa perspectiva instituinte, é preciso que professores e a cultura institucional escolar e universitária se afastem do paradigma moderno das verdades e leis universais que desqualificam saberes que não são considerados como os "válidos". É fundamental que 
sejam colocados em interatividade os diversos conhecimentos, relativizando verdades absolutas, pois tudo e todos somos passíveis de mudar e produzir mudanças com o outro.

No contexto de inovação no pensar o conhecimento e as práticas pedagógicas, o "professor, acostumado a pedir respostas de seus alunos, tem de aprender a estimular e a valorizar a pergunta. Tem de ensinar a perguntar" (CUNHA, 2016, p. 92). Assim, mais do que um conteúdo pronto a ser ensinado, o professor incorpora à sua prática o papel de mediador em diálogo com o arsenal tecnológico e produz uma sinergia de inquietude, emancipação intelectual e social de si e dos demais sujeitos envolvidos no processo de aprender com os outros. Torna-se e possibilita a formação de sujeitos interagentes no e para o uso das novas tecnologias.

\section{Sobre a estrutura das escolas e saberes docentes}

Os resultados da pesquisa apontam que todas as escolas da rede municipal de educação de Niterói têm salas de informática, mas há escolas onde elas não são usadas pelos docentes e alunos dos anos iniciais da educação básica. Há casos em que as salas de informática são disponibilizadas uma vez por semana para que os alunos utilizem os computadores como se estivessem em uma Lan House, isso quando os computadores têm acesso à Internet, o que não é generalizado na rede. Há instituições em que o laboratório de informática é usado apenas quando reservado pelos professores, para projetos e atividades pedagógicas específicas. Há escolas em que o trabalho de inclusão digital acontece de forma sistemática, por profissional qualificado para o trabalho. Há escolas com internet de baixíssima velocidade, o que provoca um grande tempo de espera para se ter acesso a sites de busca, plataformas e outros sistemas (como de jogos educativos, por exemplo). A navegação é muito lenta e, em muitos casos, intermitente. Há escolas que se localizam em bairros mais nobres da cidade, nos quais há banda larga instalada para a população de classe média e média alta e o acesso nessas unidades é muito bom.

O que podemos afirmar é que a rede pública municipal de Niterói tem buscado criar condições para que haja inclusão digital, porém a estrutura da rede digital da cidade não atende de forma equânime a população.

A manutenção dos equipamentos também não acontece de forma sistemática em todas as escolas, especialmente naquelas que ficam em bairros mais pobres e atendem às camadas mais desfavorecidas da população. Um exemplo desse processo aconteceu em 
2016, quando as bolsistas do projeto iniciaram ações em uma escola que fica próxima a duas comunidades de baixíssima renda e onde a violência do tráfico e da polícia produz grandes transtornos para os moradores, em especial para as crianças. Quando o projeto chegou à escola, imediatamente houve uma mobilização dos gestores para viabilizar o uso da sala de informática: entraram em contato com o setor responsável da Secretaria Municipal de Educação e foram consertados alguns computadores e retirados objetos impróprios ao espaço. No relatório da pesquisa, destacamos que a maioria dos educandos da Turma de Aceleração nunca havia usado um desktop com o sistema Linux, apesar de a escola ter laboratório de informática com computadores há mais de dois anos. Outra questão relevante identificada por nós foi que os alunos, com idade entre 10 e 13 anos, agrupados na Classe de Aceleração, apesar de terem nitidamente o desejo, não utilizavam o Laboratório de Informática (LI), que estava fechado e sem manutenção antes da chegada das bolsistas, que relataram em seus cadernos de campo:

Ao repassarem as redações escritas para o editor de texto, as crianças se familiarizavam com as ferramentas do sistema Linux e mesmo com o artefato desktop. Para o uso do editor de texto, os estudantes tiveram ajuda para aprender a usar e autonomia para pesquisar cada opção do programa: mexiam e remexiam nas formatações; alteravam o tamanho e o tipo de fonte e inseriam diversas formas para realçar seus textos. A turma de aceleração aprendeu a utilizar o teclado para digitar suas redações e a usar o mouse com mais segurança para efetuar seleções, além de outros comandos (Arquivo do Projeto, 2016).

Os professores de referência que participaram do projeto contribuíram e gostaram das propostas desenvolvidas com uma Classe de Aceleração, em 2016, e com outros dois grupos de referência em 2017. Expressaram interesse em aprender a usar o sistema Linux e os programas disponíveis, bem como interesse em desenvolver atividades na sala de informática da escola a partir das que propusemos, especialmente porque perceberam que algumas crianças se interessavam bastante por aprender a escrever nos computadores, o que consta no relato:

A avaliação da professora de referência foi essencial para as movimentações futuras. Em sua fala, ela relatou que a atividade mediada pelo site Escola Games, no dia 29/09/2016, foi ótima e surpreendente. Por meio dessa ação, ela pôde constatar o fato de que algumas crianças tinham muitas dificuldades na leitura e na escrita utilizando lápis e papel - antigas tecnologias -, mas utilizando os jogos interativos elas reconheceram o som das letras, conseguiram montar as palavras e expressaram mais facilmente tudo aquilo que já sabiam (Arquivo do Projeto, 2016). 
Ouvimos de alguns professores que o motivo para não usarem a sala com as crianças devia-se ao fato de desconhecerem o funcionamento do sistema Linux e estratégias que poderiam acontecer naquele espaço articuladas com os conteúdos que precisavam ser trabalhados. Afirmaram que não haviam recebido formação inicial ou continuada que possibilitasse o planejamento de ações para o uso dos artefatos. Não conheciam processos ou estratégias educacionais que pudessem ser realizadas usando os computadores.

Não foi uma descoberta surpreendente, pois essa constatação se deu também na universidade: quando iniciamos o trabalho com os bolsistas, oferecemos oficinas no Laboratório de Informática da FEUFF (LIFE), que esteve fechado para os graduandos por dois anos devido à falta de um docente responsável por ele. Nas oficinas, ocorria a experimentação do sistema Linux, desconstruindo a ideia dominante de que este sistema era "muito complicado". A maioria dos bolsistas que inicia suas atividades no projeto não tem habilidade para o uso desse sistema operacional, embora possuam alguma para outros sistemas. Uma publicação da Unesco Brasil (2008) explicita que a formação do professor para a utilização das TICs nas práticas educativas é secundarizada pelo governo federal com relação à compra de computadores e de programas educativos. Tal perspectiva política vem dificultando ainda mais a interação aluno-professor-novas tecnologias no cotidiano escolar, denotando que:

Muitas vezes a inovação é compreendida como a inclusão de aparatos digitais e tecnológicos nas instituições de ensino. Entretanto, essa é uma forma reducionista de abordar o tema. É preciso reinventar o papel da escola e da universidade nesse novo contexto, e uma das razões que sustentam esse intento é assumir que há diferença entre informação e conhecimento (CUNHA, 2016, p. 92).

O acesso aos conhecimentos profissionais necessários para o uso das TICs na educação básica requer uma interação teórico-prática que possibilite aprender a lidar com essas ferramentas e refletir sobre seus usos e abusos. Demanda, em sua formação inicial e continuada, experiências educacionais de compartilhamento de conhecimento para sistematização de processos inovadores que potencializem pensares-fazeres pedagógicos em diálogo com a cibercultura, como sujeito interagente.

Hoje, há um discurso de que as novas gerações são "naturalmente" participantes da cibercultura. Isso não é totalmente verdade para as pessoas que vêm das classes populares. Muitos alunos são usuários da tecnologia, assim como os docentes das universidades e das 
escolas, mas precisam desenvolver um diálogo crítico com o mundo cibernético, formando-se enquanto sujeitos interagentes.

Silva (2010, p. 42) afirma que, na "cibercultura, ocorre a transição da lógica da distribuição (modalidade unidirecional) para a lógica da comunicação (modalidade interativa)". Para uma educação inovadora, em diálogo com a cibercultura, faz-se necessária a

[...] modificação radical no esquema clássico da informação baseado na ligação unilateral emissor-mensagem-receptor: a) o emissor não emite mais, no sentido que se entende habitualmente, uma mensagem fechada; oferece um leque de elementos e possibilidades à manipulação do receptor; b) a mensagem não é mais "emitida", não é mais um mundo fechado, paralisado, imutável, intocável, sagrado, é um mundo aberto, modificável na medida em que responde às solicitações daquele que a consulta; c) o receptor não está mais em posição de recepção clássica; é convidado à livre criação, e a mensagem ganha sentido sob sua intervenção (SILVA, 2010, p. 42).

Levadas a pensar sobre o fato de que a não apropriação desses conhecimentos na formação inicial refletiria nas ações dos futuros licenciados, Dominick e Freitas, em $2013^{3}$, realizaram uma enquete entre estudantes do curso de Pedagogia da FEUFF e identificaram baixíssima oferta de disciplinas abordando o trabalho com as tecnologias informacionais eletrônicas no ensino. Chegaram a essa conclusão por meio de levantamento com dez bolsistas que participavam de um projeto e que apontaram poucas disciplinas dialogando minimamente com o uso das tecnologias na educação. Foram citadas as disciplinas "Comunicação e Linguagem" e "Educação Especial". Além da resposta das bolsistas, foi feita uma entrevista fechada com 30 alunos concluintes, e estes afirmaram não identificar no curso efetivo trabalho com o tema, de modo a contribuir com a formação profissional para lidar com as novas tecnologias como mediadoras de conhecimento.

Percebendo a necessidade de discutir no curso de Pedagogia em Niterói a temática das tecnologias educacionais e informacionais, foram apresentados projetos de Extensão, de Inovação em Tecnologia Social (PIBITI), ao Programa de Bolsa de Iniciação Científica (PIBIC) e de Licenciatura, buscando ampliar o número de estudantes de Pedagogia envolvidos no estudo, na reflexão e na elaboração de práticas pedagógicas em interconexão com as tecnologias informacionais e em diálogo com a diversidade, com princípios 
inclusivos e democráticos. Desses projetos nasceram monografias e artigos publicados que expressam as descobertas, invenções e reinvenções dos graduandos em diálogo com as tecnologias informacionais e outras disponíveis na escola. Em um dos primeiros trabalhos assinados por bolsistas do projeto que foram publicados em revista acadêmica, em 2013, sobre o tema tecnologia ${ }^{4}$, relatamos as conexões feitas entre as tecnologias e a inclusão de pessoas com deficiência em escolas regulares e como o conhecimento sobre as tecnologias assistivas e as tecnologias assistivas informacionais foram incorporados ao trabalho.

No processo de inovação pedagógica, as bolsistas contam-nos:

Iniciamos o trabalho com um Power Point do livro "Na minha escola todo mundo é igual", de Rossana Ramos, que trata da diversidade humana no ambiente escolar. Queríamos mostrar aos alunos que todas as pessoas possuem capacidades e são merecedoras de respeito. $\mathrm{O}$ objetivo foi alcançado quando vimos que os alunos relacionavam a história do livro com suas vivências (MARTINEZ; LABELLE; DOMINICK, 2014, p. 7$)^{5}$.

Em 2015, uma das bolsistas havia se tornado professora de apoio (para alunos com deficiência) na escola e, em diálogo com outras duas docentes da unidade e com o nosso grupo de pesquisa, desenvolveu um projeto profundamente articulado aos princípios da Tecnologia Social. O resultado desse processo foi publicado com o título "Ações

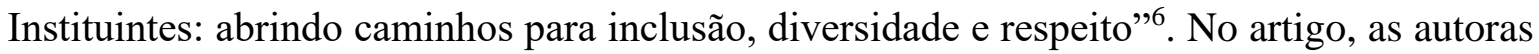
concluem:

[...] Perceber e conversar sobre nossas imperfeições como docentes possibilitou que os alunos identificassem o quanto ser excluído pelas diferenças é negativo e doloroso.

O conjunto de ações desenvolvidas com os discentes trouxe aprendizados para eles e também para nós, docentes. No processo de reflexão e busca de caminhos para o trabalho com as temáticas fomos olhando e descobrindo que precisávamos também mudar nossas práticas (SILVA; DOMINICK; MATTOS; ABREU, 2015, p. 123).

Em 2017, partindo do relatório de pesquisa de 2014, foi publicado um artigo ${ }^{7}$ no qual as docentes que foram bolsistas do projeto narram algumas vivências em uma sala de

\footnotetext{
${ }^{4}$ Disponível em: <http://www.revistaleph.uff.br/index.php/REVISTALEPH/article/download/386/293>.

${ }^{5}$ Disponível em:

<http://www.cap.uerj.br/site/images/stories/noticias/19-martinez_et_al.pdf >.

${ }^{6}$ Disponível em:

<http://revistaleph.uff.br/index.php/REVISTALEPH/article/download/209/142>.

${ }^{7}$ Disponível em:

<http://revistaleph.uff.br/index.php/REVISTALEPH/article/view/639/0>.
}

RIAEE - Revista Ibero-Americana de Estudos em Educação, Araraquara, v. 13. n. esp. 2, p. 1334-1358, set., 2018. ISSN: $1982-5587$. 
recursos multifuncional e a maneira inovadora como a professora do espaço se apropriava da tecnologia informacional para o trabalho com uma criança com deficiência:

\begin{abstract}
O aluno ficou empolgado e foram para o computador. Neste momento, o ensino da língua portuguesa havia feito uma ponte interdisciplinar e, a partir da tecnologia assistiva confeccionada artesanalmente pela professora, seguiu-se um trabalho com a tecnologia informacional computadorizada. Conectados à internet, foram pesquisando sobre a temática de interesse do estudante. Durante a navegação abriu-se um leque de possibilidades e aconteceram conversas sobre o meio ambiente e a reprodução do animal. A docente comentou e explicou a necessidade de se preservar o lugar onde as tartarugas colocam os ovos e que as características do animal se alteram de acordo com o ambiente onde nascem. A Geografia apareceu por meio das informações relativas às ilhas de Galápagos, no Equador. $\mathrm{O}$ peso de até 400 quilos, o comprimento de até 1,8 metro e o tempo de vida das tartarugas possibilitaram a conexão com os conteúdos matemáticos que, posteriormente, foram explorados pela docente em outras atividades (MESQUITA; SILVA; DOMINICK, 2017, p. 217).
\end{abstract}

Passamos também a oferecer, a partir do primeiro semestre de 2016, uma Atividade Cultural denominada "Artes de fazer, de usar e recriar, tecnologias nos anos iniciais" para alunos do curso de Pedagogia, usando os computadores com o sistema Linux do Laboratório de Informática da FEUFF. A oferta da Atividade Cultural teve como foco realizar reflexões, pesquisas e práticas sobre o uso das novas tecnologias e o diálogo destas com as tecnologias tradicionais presentes nas escolas. Tivemos duas boas experiências. Sempre iniciamos ouvindo os alunos sobre o que eles sabem e sobre o que gostariam de saber. Perguntamos a eles sobre como fazer para aprendermos o que desejam. É explicitado que o curso não pode acontecer sem que eles se envolvam e proponham caminhos. Assim, vamos construindo juntos o caminhar e construindo conhecimentos sobre a cultura da partilha, o sistema Linux, o uso do Dropbox como recurso de armazenamento online das pesquisas e produções do grupo. Já experimentamos a criação de página no Facebook (https://www.Facebook. com/tecnologiaepedagogia/), e-book, e exploramos a criação de vídeos como mecanismo para avaliação da disciplina (https://www.youtube.com/channel/UCFphOtePwvKWC37hWHinsXg https://www.youtube.com/playlist?list=PLYSCjBjnb_1YLD7XbEHOha7hZeTR1Wgn).

Nosso trabalho final tem sido a elaboração de um pré-projeto interdisciplinar colocando em diálogo as tecnologias informacionais e temas contemporâneos de interesse dos licenciandos. Experimentamos a produção do esboço de artigo com digitação online e simultânea pelo coletivo (Disponível em: <linksharing>). 
Desse processo nasceu o trabalho que foi enviado à Mostra de Iniciação Científica da UFF em 2017. Uma proposta construída a partir da cultura da partilha que despontou da busca por uma pedagogia inovadora na formação de professores para os anos iniciais da educação básica.

Imagem 1: Pôster elaborado a partir de resumo enviado à Mostra PIBIC UFF 2017

\section{NOVAS E TRADICIONAIS TECNOLOGIAS NOS ANOS INICIAIS DA EDUCAÇÃO BÁSICA E A FORMAÇÃO DE PROFESSORES 2016}

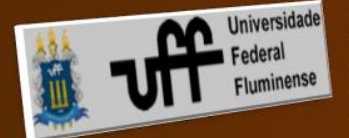

INTRODUÇĀO

Relatamos experiência de investigação sobre uso e disponibilidade das novas (echologlas na UFF, mas espechicamente o Quadro Interativo (QI) ou Lousa Interativa. O trabalho foi desenvolvido durante aulas da Atividade Cultural Artes de fazer, de usar e recriar tecnologias nos anos iniciais, para alunos de Pedagogia da Faculdade de Educação.

- O foco do trabalho: realizar reflexōes, pesquisas e práticas sobre o uso das novas tecnologias e o diálogo destas com as tecnologias tradicionais presentes na escola.

Planejamento Participativo: os estudantes indicaram interesse em aprofundar conhecimentos sobre o uso do QI - sabíamos da existência de alguns no Campus e nenhum de nós havia vivenciado o seu uso durante aulas ou palestras.

Caminho para concretizar: pesquisa na internet, conversas com servidores - Ććnicos administativos, pesquisa em alouns blocos do Campus e agendamento das salas 306 do Bloco A e a sala 501 do Bloco C.

RESULTADOS E DISCUSSŌES:

Frustação com o uso na UFF, decisão de escrita colaborativa da Frustaçáo com o uso na UFF, decisáo de escrita colaborativa da (Shirky, 2011) na perspectiva da produçäo colaborativa (Pretto, 2010) e dos movimentos colaborativos (Bonilla e Pretto, 2015. Dialogamos ainda com as on

Nos reunimos no Laboratório de Informática da FEUFF para aprender a usar o Google Drive. O aluno RMS nos ensinou a fazer a conexão simultâne para a redaçao colabotiva. O DESAFIOS FRENTE A TECNOLOGIA EDUCACIONAL, a aulapesquisa estava nos mostrava uma jornada intrincada para concretizar o que haviamos nos proposto.

Visita à escola para ver o quadro funcionando: Dois alunos agendaram visita a escola e conseguimos ver acontecendo uma aula real com o artefato. Fomos recebidos pelo técnico de informática que falou sobre o funcionamento e proposta pedagógica da escola para uso da tecnologia. O QI que a escola usa funciona por espelhamento e se torna interativo através do uso do Ipad. A escola disponibiliza um tablete para o professor levar para casa e incluir o material que deseja. O professor posta filmes fotos, PPT, textos, música, além do que já tem pré-programado. O técnico Wigor é o único da escola e responsável por agendar atividades coletivas e dar o suporte necessário aos usuérios. Funciona com plataforma UNO.

CONCLUSŌES:

Essa experiêncialaula/pesquisa gerou reflexões, entre elas sobre a compra de Q na UFF, que precisa ser repensada na medida em que o STI năo dá qualque apoio para seu funcionamento. Pensamos também que não houve planejamento estratégico e nem participativo para a compra de tais artefatos. Não identificamos conexäo com a proposta de Tecnologia Social.

A hipótese de que os QI não eram usados porque os professores não sabiam A hipótese de que os Ql não eram usados porque os professores náo sabiam usa-los estava parcialmente correta, pois percebemos que os QI disponiveis nos Blocos pesquisados estavam com programas não mais disponiveis ou que não foram atualizados. O STI da UFF não dá apoio ao professore que deseja usar o

Foi uma experiência que nos possibilitou discutir sobre os interesses econômicos envolvidos na compra de equipamentos para a educaçäo e sobre a necessidade cada vez maior de dominarmos diferentes conhecimentos que envolvem trabalho do Pedagogo, entre eles uma outra língua, além da materna, principalmente o Inglês.

Como afirma Dominick (2013), "é preciso pensar complexamente para entender que as tecnologias não estão separadas da nossa existência e com elas interagem as macro e micro politicas os projetos sociais, os interesses econômicos e de poder".

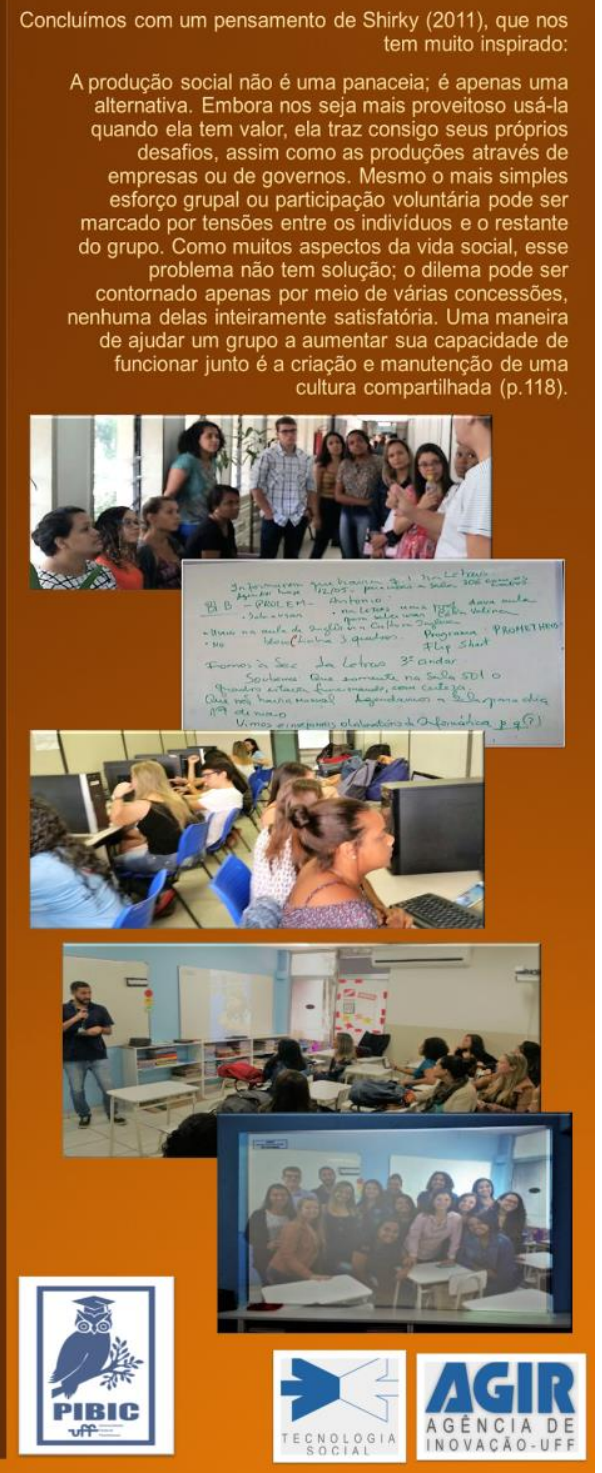

Fonte: Arquivo do projeto "Novas e tradicionais tecnologias nos anos iniciais da educação básica e a formação de professores" (2016).

RIAEE - Revista Ibero-Americana de Estudos em Educação, Araraquara, v. 13. n. esp. 2, p. 1334-1358, set., 2018. ISSN: $1982-5587$. DOI: 10.21723/riaee.v13.nesp2.set2018.11647 


\section{Considerações finais}

A aproximação da universidade com a escola permite-nos perceber que essa interação é fundamental para compreendermos a inovação pedagógica como um processo que precisa ser construído dentro da perspectiva da cultura inclusiva.

Hoje, mais do que nunca, é preciso repensar de forma integrada as transformações necessárias à cultura institucional escolar e universitária, pois o diálogo entre sujeitos e saberes diversos é o que possibilitará a construção de propostas que conectem a educação básica e a formação de professores ao novo mundo, que está cada vez mais integrado pelas tecnologias digitais da informação e da comunicação.

Para potencializarmos tal conexão, precisamos nos mobilizar em direção à construção de conhecimentos mais coletivizados, colaborativos, com conteúdos mais flexíveis, em diálogo com os interesses de uma geração que aprende de forma muito distinta daquela que pensou a escola ainda hegemônica.

A educação escolar com as dimensões que permeiam as interações estabelecidas no espaço cibernético pode reconfigurar elementos que modifiquem e ampliem o alcance das ações educativas. A incorporação das novas tecnologias informacionais na escola e na universidade demanda, no entanto, que os docentes se apropriem delas como mediadores entre os estudantes e os diversos conhecimentos que hoje podem ser acessados, construindo novas formas de relacionamento no processo. Uma formação inovadora contribuirá para a criação de novas pontes que possibilitem a transposição de uma sociedade e de uma escola que, em geral, separa o mundo de dentro do mundo de fora para uma que aceita as tensões sociais e cognitivas propostas, interagindo com elas de forma a superar o ainda grande processo de exclusão que permeia a sociedade e as instituições educacionais.

Pensar o currículo para além de elencar disciplinas e conteúdos consiste na possibilidade de construção de processos participativos em que alunos e docentes se articulam para aprenderem juntos a dialogar com a cibercultura de maneira a se tornarem sujeitos interagentes nesse mundo virtual, que se embrenha no real e do qual todos têm direito de participar com suas singularidades.

As reflexões e análises sobre essa conjuntura ainda estão em processo, mas reconhecemos como relevante a reflexão sobre as tecnologias como ferramentas de interatividade e colaboração, que consideramos intimamente ligadas aos conceitos de inclusão, inovação pedagógica e emancipação. $\mathrm{O}$ acesso às tecnologias digitais no contexto 
educacional e no cotidiano pode proporcionar - sob uma perspectiva crítico-reflexiva uma reorganização das relações sociais, rumo a um processo de cidadania crítica, emancipatória e autônoma. No contexto dessa proposta, ensejamos educar para uma sociedade multicultural e inclusiva, respeitando a diversidade dos conhecimentos advindos dos sujeitos históricos que compõem o cotidiano do contexto educativo e produzem encontros desveladores de elementos que apontam para o necessário e constante diálogo.

Em interação com o processo de pesquisa, ensino e extensão, a escola e a universidade podem desenvolver coletivamente tecnologias sociais que promovam iniciativas de práticas inovadoras, igualitárias e inclusivas, a fim de desenvolver melhorias dos contextos social e educacional brasileiros.

AGRADECIMENTOS: CNPq, PROPPI-UFF, PROEX-UFF, PROGRAD-UFF, Programa Licenciaturas-UFF, FME-Niterói, direção e funcionários da FEUFF, chefia do SSE, bolsistas dos projetos aqui apresentados, professores e gestores das escolas que participaram dos projetos, estudantes de graduação que participaram dos projetos.

\section{REFERÊNCIAS}

ABRIC, J-C. Pratiques sociales et représentations. Paris: PUF, 1994.

ABRIC, J-C. A abordagem estrutural das representações sociais. In: MOREIRA, A.S.P.; OLIVEIRA, D.C. (Org.) Estudos interdisciplinares de representação social. Goiânia: AB Editora, 2000. p. 27-39.

BARDIN, L. Análise de conteúdo. Lisboa: Edições 70, 2006.

BONILLA, M. H. S.; PRETTO, N. de L. Política educativa e cultura digital: entre práticas escolares e práticas sociais. PERSPECTIVA, Florianópolis, v. 33, n. 2, p. 499 - 521, maio/ago. 2015.

BRANDÃO, C. R. (Org.). Repensando a pesquisa participante. 3. ed. São Paulo: Brasiliense, 1987.

BRANDÃO, C. R. (Org.). Pesquisa participante. São Paulo: Brasiliense, 1990.

BRANDÃO, C. R. A pergunta a várias mãos: a experiência da pesquisa no trabalho do educador. São Paulo: Cortez, 2003.

CASTELLS, M. A era da informação: economia, sociedade e cultura. 6. ed. São Paulo: Paz e Terra, 1999a. v. 1. 
CASTELLS, M. A era da informação: fim de milênio. São Paulo: Paz e terra, 1999b. v. 3.

CASTELLS, M. A sociedade em rede. São Paulo: Paz e Terra, 2002.

COSTA, A. B.; JESUS, V. M. B. de. Tecnologia social: breve referencial teórico e experiências ilustrativas. In: COSTA, Adriano Borges (Org.). Tecnologia social e políticas públicas. São Paulo: Instituto Pólis; Brasília: Fundação Banco do Brasil, 2013. p. 17-31.

CUNHA, M. I. Inovações na educação superior: impactos na prática pedagógica e nos saberes da docência. Revista Em Aberto, v. 29, n. 97, p 87-101, set./dez., 2016.

GATTI, B. A. Formação de professores: condições e problemas atuais. Revista Internacional de Formação de Professores (RIFP), Itapetininga, v. 1, n. 2, p. 161-171, 2016.

GÜNTHER, H.; ELALI, G.A.; PINHEIRO, J.Q. A abordagem multimétodos em estudos pessoa-ambiente: características, definições e implicações. In: GÜNTHER, H.; PINHEIRO, J.Q. Métodos de pesquisa nos estudos pessoa-ambiente. São Paulo: Casa do Psicólogo, 2008. Disponível em: <www.psiambiental.net/XTextos/20MultiMetodo.pdf>. Acesso em: 14 jun. 2017.

ITS (Instituto de Tecnologia Social). Tecnologia social: uma estratégia para o desenvolvimento. In: ITS. Tecnologia social: uma estratégia para o desenvolvimento. Fundação Banco do Brasil, Rio de Janeiro: 2004. p. 117-133. Disponível em: $<$ http://www.itsbrasil.org.br/infoteca/tecnologia-social/tecnologia-social-uma-estrategiapara-o-desenvolvimento>. Acesso em: 15 out. 2013.

JODELET, D. Representações sociais: um domínio em expansão. In: JODELET, D. (Org.). As representações sociais. Rio de Janeiro: Editora UERJ, 2001.

JOHNSON, B.; ONWUEGBUZIE, A. Mixed methods research: A research paradigm whose time has come. Educational Researcher, v. 33, p. 14-26, 2004.

LÉVY, P. Cibercultura. São Paulo: Editora 34, 1999.

LUDKE, M.; ANDRÉ, M. A pesquisa em educação: abordagens qualitativas. São Paulo: EPU, 1986.

MAMEDE-NEVES, M. A. C.; DUARTE, R. O contexto dos novos recursos tecnológicos de informação e comunicação e a escola. Educação e Sociedade, Campinas, v. 29, n. 104, Especial, p. 769-789, out., 2008.

MATTOS, C. L. G. de. A abordagem etnográfica na investigação científica. Revista Espaço (INES), n. 16, p. 42-59, jul.-dez. 2001.

MATTOS, C. L. G. de. Estudos etnográficos da educação: uma revisão de tendências no Brasil. Educação em Foco, Juiz de Fora, v. 2, p. 39-57, 2006. 
MATTOS, C. L. G. de. Etnografias na escola: duas décadas de pesquisa sobre o fracasso escolar no ensino fundamental. In: MATTOS, C. L. G. de; FONTOURA, H. A. de (Org.). Etnografia e educação: relatos de pesquisa. Rio de Janeiro: EdUERJ, 2009.

MOSCOVICI, S. O fenômeno das representações sociais. DUVEEN, In: G. (Org.). Representações sociais: investigações em psicologia social. Petrópolis: Vozes, 2003. p. 29-109.

PRETTO, N. L.; ASSIS, A. Ensaio: cultura digital e educação: redes já! In: PRETTO, N. L.; SILVEIRA, S.A. (Org.). Além das redes de colaboração: internet, diversidade cultural e tecnologias do poder. Salvador: EDUFBA, 2008. p. 75-83. [online]. Disponível em: <http://books.scielo.org>. Acesso em: 10 jan. 2018.

PRETTO, N. L.; PINTO, C.C. Tecnologias e novas educações. Revista Brasileira de Educação, v. 11, n. 31, jan.-abr. 2006. [online].

SILVA, M. Educar na cibercultura: desafios à formação de professores para docência em cursos online. Revista Digital de Tecnologias Cognitivas, São Paulo, n. 3, p. 36-51, 2010.

THIOLLENT, M. Metodologia da pesquisa-ação. São Paulo: Cortez, 1994.

UNESCO BRASIL. Computador na escola - o futuro anunciado. Revista TICs nas Escolas, v. 3, n. 2, 2008.

\section{Como referenciar este artigo}

DOMINICK Rejany dos Santos, ALVES Walcéa Barreto. Inclusão Digital e Inovação Pedagógica: Diálogo Necessário. Revista Ibero-Americana de Estudos em Educação, Araraquara, v. 13. n. esp. 2, p. 1334-1358, set., 2018. ISSN: 1982-5587. DOI: 10.21723/riaee.v13.nesp2.set2018.11647

Submetido em: 15/02/2018

Aprovado em: 01/04/2018 